\title{
FIRST RESULTS ON THE DIRECTION STATISTICS OF PAIRS OF EPICENTERS OF NEIGHBOR EARTHQUAKES ON KAMCHATKA
}

\author{
A. A. Gusev1,2, A. A. Palueva1 \\ ${ }^{1}$ Institute of Volcanology and Seismology, Far East Branch of RAS, Petropavlovsk-Kamchatsky, Russia \\ ${ }^{2}$ Kamchatka Division of Geophysical Survey of RAS, Petropavlovsk-Kamchatsky, Russia
}

\begin{abstract}
Small earthquakes, often treated as "background seismicity", are not distributed in space-time in a random manner. Often, space-time clustering is studied, that manifests itself as aftershock sequences and swarms. These phenomena can be described as a deviation (increase) of probability of short interevent distances and times as compared to the reference "pure random" or Poisson case; this tendency manifests itself in statistics of distances between epicenters. In the present work, we study the statistics of directions for vectors connecting pairs of epicenters of such small earthquakes which are close in space-time. Components of such pairs will be called "neighbors", and the mentioned vectors will be called "link vectors". A study of this kind is of interest from a number of viewpoints, such as: discovering new properties of statistical structure of observed fields of epicenters; establishing interactions between earthquake sources of small earthquakes, revealing geometrical properties of the pattern of active faults of a low rank. We will show that directions of link vectors clearly deviate from isotropy, and have instead non-uniform, often spiked,
\end{abstract} distribution of directions.

Pairs of neighbors are extracted from the catalogue of small $\left(M_{\mathrm{L}}=3.5-5.0\right)$ shallow earthquakes of the Kamchatka subduction zone. To define neighbors, bounds are set on the distance $(10-60 \mathrm{~km})$ and relative delay (0.5 day) between members of a pair. Before pair extraction, the work catalog was decimated to reduce space-time event density within dense clusters. With the catalog of pairs at hand, we constructed distributions of azimuths of link vectors (rose diagrams of directions). In Fig. 3 one can see example histograms and corresponding rose diagrams for two 10-year periods (see Table 1 for definitions and labels of the periods); processing was done using two variants of maximum delay: 0.5 and 5 days. Angles (modified azimuths, $v$ ) in all histograms and rose-diagrams are counted off from the direction with azimuth of $37^{\circ}$ that represents the strike of the island arc. Before constructing rose diagrams, the modified azimuths were reduced to the $\left[0^{\circ} 180^{\circ}\right]$ range by subtracting $180^{\circ}$ when needed. One can see that with the stricter limit of 0.5 days, histograms and rose diagrams show more expressed deviations from the uniform (isotropic) distribution of angles. For both variants of the maximum delay, the along-arc oriented pairs manifest themselves (at $v$ about $0^{\circ}$ and $180^{\circ}$ ). At the less strict limit of 5 days, this orientation begins to dominate. Although this tendency formally means a break of isotropy, it is not of particular interest because it results from the fact that a large fraction of epicenters occupy a relatively narrow strip, well seen on Fig. 1; therefore the observed $0-180^{\circ}$ preferred direction has no connection to epicenter distribution within narrow space-time neighborhoods that we intend to analyze.

To suppress the contribution of this interfering direction, a special normalization of angle histograms was performed. We additionally calculated similar histograms for larger delays, 100 to 150 days, marked T, considering these as representing pure effect of geometry of the epicenter field, and used them for normalization, performed in the following way. Values of the initial or raw (R) histograms are divided (point by point) by corresponding values of Thistograms. In this way the normalized $(\mathrm{N})$ histograms are obtained, considered as most representative of preferred directions of neighbor pairs. To make the results more convincing, we performed statistical testing of the hypothesis "N-histogram differs from a constant"; actually, the equivalent hypothesis "the R-histogram differs from the Thistogram" was tested. The Pearson's $\chi^{2}$ criterion was used. The significance value, $Q$, is indicated on plots, in most cases it is below $0.1 \%$. Such are the processing procedures employed; then the analysis of data was performed.

$\mathrm{N}$-histograms have been determined for three circles of the 150-km radius shown on Fig. 1, and for five ten-year periods. For the corresponding R-, T- and N-histograms and rose diagrams see Fig 5, 4 and 6. One can see a clear and mostly significant deviation from isotropy; instead, narrow petals are seen in many cases. To see in the original map view how these petals are formed see Figs 7 and 8.

The following conclusions can be derived from this material. (1) The observed distributions of pair azimuths deviate significantly from the uniform law; in many cases, this deviation manifests itself as narrow petals. (2) In two out of three rose diagrams of $\mathrm{N}$ kind, there is an expressed petal oriented across the island arc, and along the maximum compression axis. Its formation is difficult to explain from the geomechanical viewpoint. (4) There is evident difference between the rose diagrams for the two southern circles SK and SP, located in the main part of the island arc, and 
that for the circle KG located near to the junction of Kurile-Kamchatka and Aleutian arc. (5) Clear temporal variations of rose diagrams are seen; these can reflect short-term evolution of parameters of seismotectonic deformation (of "seismic flow of rock masses" in terms by B.V. Kostrov [Kostrov, 1974, 1975]). We believe that the observed picture can be explained through propagation of pulses of aseismic slip along secondary faults. Such pulses are accompanied by small earthquakes; in this way, a pattern of oriented epicenter pairs arises, akin to the notion of migration of epicenters. The location of oriented pairs is tied to several hypothetic systems of subparallel (en-echelon) faults; each such system is manifested as an individual petal of a rose diagram. This interpretation is illustrated by Figs 7 and 8 where one can see in map view how a separate petal of a rose diagram is related to a set of subparallel links that formed it. The main result of the study is the design and testing of a new technique of investigation of hidden anisotropy of the field of epicenters, and detection of time variations of the revealed features. The technique has a potential for monitoring the stress regimen of the lithosphere.

Key words: epicenter; background seismicity; space-time; geometry; direction; lineament; en-echelon fault; migration; rose diagram

Recommended by V.S. Imaev

For citation: Gusev A.A., Palueva A.A. 2016. First results on the direction statistics of pairs of epicenters of neighbor earthquakes on Kamchatka. Geodynamics \& Tectonophysics 7 (4), 529-543. doi:10.5800/GT2016-7-4-0221.

Для цитирования: Гусев А.А., Палуева А.A. Первые результаты исследования статистики направлений для пар эпицентров землетрясений-соседей на Камчатке // Геодинамика и тектонофизика. 2016. T. 7. № 4. C. 529-543. doi:10.5800/GT-2016-7-4-0221.

\title{
ПЕРВЫЕ РЕЗУЛЬТАТЫ ИССЛЕДОВАНИЯ СТАТИСТИКИ НАПРАВЛЕНИЙ ДЛЯ ПАР ЭПИЦЕНТРОВ ЗЕМЛЕТРЯСЕНИЙ-СОСЕДЕЙ НА КАМЧАТКЕ
}

\author{
А. А. Гусев ${ }^{1,2}$, А. А. Палуева ${ }^{1}$ \\ ${ }^{1}$ Институт вулканологии и сейсмологии ДВО РАН, Петропавловск-Камчатский, Россия \\ ${ }^{2}$ Камчатский филиал Геофизической службы РАН, Петропавловск-Камчатский, Россия
}

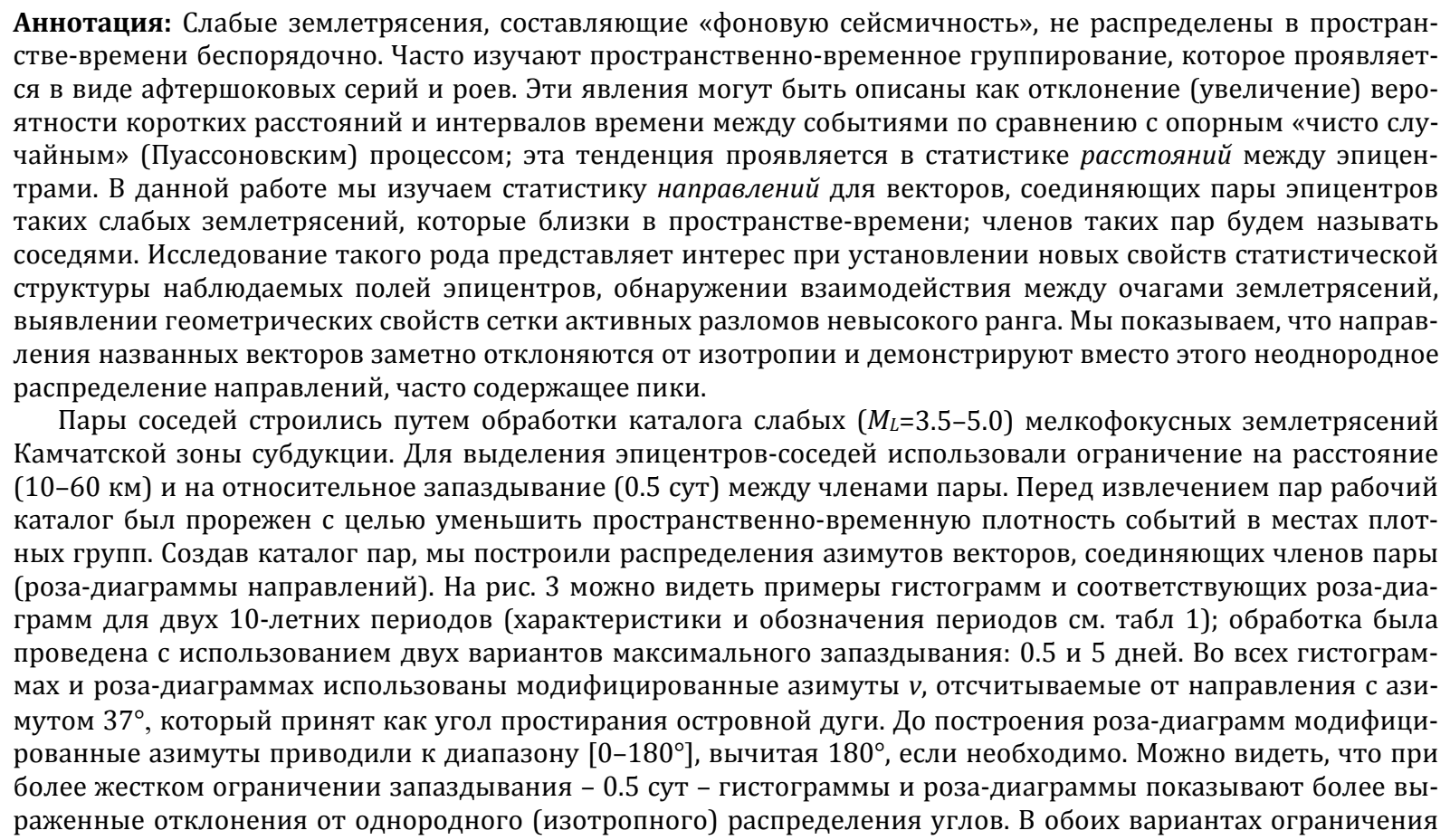


запаздывания проявляются пары, ориентированные вдоль дуги (на углах вблизи $0^{\circ}$ и $180^{\circ}$ ). При менее жестком ограничении (5 сут) это направление начинает доминировать. Его появление можно было ожидать: оно отражает преимущественное распределение эпицентров в относительно узкой полосе (хорошо заметной на рис. 1). Эта тенденция никак не связана со спецификой поведения именно «соседей». Чтобы подавить вклад этого мешающего направления, была проведена специальная нормализация угловых гистограмм. Подобные гистограммы рассчитали для больших задержек, 100-150 дней (обозначены Т), и рассматривали их как проявление чистого эффекта геометрии поля эпицентров. Значения исходных R-гистограмм были разделены (поточечно) на соответствующие значения T-гистограмм. Таким путем получали нормализованные N-гистограммы. Считали, что они наилучшим образом характеризуют предпочтительные направления пар соседей. Для исключения субъективных результатов выполняли статистический контроль гипотезы «N-гистограмма отличается от постоянной»; для этого проверяли эквивалентную гипотезу «R-гистограмма отличается от Т-гистограммы». Использовали критерий $\chi^{2}$ Пирсона. Уровень значимости, $Q$, обозначен на графиках, в основном, он ниже $0.1 \%$. Таковы методические основы работы, используемые при анализе данных.

$\mathrm{N}$-гистограммы были определены для трех кругов радиуса 150 км, показанных на рис. 1, и для пяти десятилетних периодов. Соответствующие R-, T- и N гистограммы и роза-диаграммы см. на рис. 5, 4 и 6. Можно видеть выраженное и почти везде значимое отклонение от изотропии; вместо этого во многих случаях заметны узкие лепестки. На рис. 7 и 8 приводятся примеры, поясняющие, чему соответствуют эти лепестки на исходной карте. Из этого материала можно сделать следующие выводы. (1) Наблюдаемое распределение азимутов пар существенно отличается от равномерного закона; во многих случаях это отклонение проявляется в виде узких лепестков направленности. (2) В роза-диаграммах вида N часто присутствует выраженный лепесток, ориентированный поперек островной дуги и вдоль оси наибольшего сжатия. Возникновение такого лепестка трудно объяснить с позиций геомеханики. (3) Имеет место очевидное различие между розадиаграммами для двух южных кругов SK и SP, расположенных в основной части островной дуги, и таковыми для круга KG, расположенного вблизи стыка Курило-Камчатской и Алеутской дуг. (4) Имеются явные вариации роза-диаграмм во времени, что может указывать на кратковременные изменения параметров сейсмотектонической деформации («сейсмического течения горных масс» по Б.В. Кострову [Kostrov, 1974, 1975]). Мы полагаем, что наблюдаемая картина может быть объяснена на основе представления о распространении вдоль вторичных разломов импульсов асейсмического скольжения. Такие импульсы сопровождаются слабыми землетрясениями. Таким образом, возникает картина множества ориентированных пар эпицентров, она близка к идее миграции эпицентров. Расположение ориентированных пар привязано к нескольким гипотетическим системам субпараллельных (эшелонированных) разломов, каждая такая система проявляет себя в формировании индивидуального лепестка роза-диаграммы. Эта интерпретация понятна из рис. 7 и 8 , где можно видеть, как отдельный лепесток роза-диаграммы соотносится с множеством субпараллельных пар эпицентров, которые его сформировали.

Результат исследования - разработка и опробование новой методики определения скрытой угловой анизотропии поля эпицентров, обнаружение временных вариаций выявленных особенностей. В перспективе методика имеет потенциал для задачи слежения за активными процессами в литосфере.

Ключевые слова: эпицентр; фоновая сейсмичность; пространство-время; геометрия; направление; линеамент; эшелонированный разлом; миграция; роза-диаграмма; временные вариации

\section{1. ВВЕДЕНИЕ}

Слабая «фоновая» сейсмичность сейсмоактивных зон обычно формирует рассеянное, квазислучайное поле эпицентров. Хорошо известное свойство этого поля - группирование в виде афтершоковых серий, роев и др. Другое типичное явление формирование линейных структур, часто маркирующих сейсмоактивные геологические разломы. Полосы эпицентров вдоль разломов характерны для зон с преобладанием сдвигов; в зонах с преобладанием взбросов и сбросов картина менее четкая. В зонах субдукции вдоль субдукционного взброса формируется широкая полоса эпицентров; ее внутренняя структура обычно выражена недостаточно ясно. На Камчатке фоновая мелкофокус- ная сейсмичность, связанная с пологим субдукционным меганадвигом, прослеживается в плане в виде полосы шириной более 100 км.

Исследования геометрии эпицентров, линеаментов, ими образуемых (площадок в трехмерном случае), и связи этих объектов с активными разломами или границами жестких литосферных блоков различного масштаба весьма распространены. Для сильных землетрясений эта связь общеизвестна. Для слабой сейсмичности имелись попытки выделить структуры из поля эпицентров или гипоцентров [Amorese et al., 1999; Jones, Stewart, 1997; Ouillon et al., 2008]. Однако фактор времени при выделении структур во внимание не принимался. Время существенно используется при исследовании миграции эпицентров [Richter, 1958; Mogi, 1968; Vil'kovich, 
Shnirman, 1980; и $\partial p$.], но в этих работах геометрия структур, вдоль которых шла миграция, специально не изучалась. П.Н. Шебалин [Shebalin, 2005] ввел термин «очаги-соседи», где критерием соседства является близость в пространстве и времени, и использовал понятие «цепочки» для группы соседей; он, однако, не интересовался деталями геометрии такой «цепочки».

В важной серии исследований А.А. Лукк $[L u k k$, 1978] и А.А. Лукк и И.В. Турчанинов [Lukk, Turchaninov, 1998] отметили формирование кратковременных линейных цепочек эпицентров в Гармском районе Таджикистана. Цепочки в терминологии А.А. Лукка состояли из пяти и более эпицентров землетрясений с $M \geq 1$, произошедших за короткое время в прямолинейной полосе шириной 3-5 км и длиной 30-110 км. Расстояние между звеньями цепочки не превышало 25-40 км, слишком малые расстояния не допускались. Интервал времени между звеньями цепочки - до 1 сут, полная длительность - до 5-7 сут. При выделении цепочек устанавливали предел на разность номеров событий в каталоге. Реальность явления возникновения цепочек проверялась путем сравнения результатов их выделения с аналогичными результатами для рандомизованной версии каталога. Результаты описанных детальных работ выглядят весьма убедительно. Однако формальный статистический контроль реальности явления не проводился. В этих работах получены важные первые результаты по угловой структуре серий соседей. Предмет исследования весьма интересен и явно заслуживает изучения.

В настоящей работе изучаются структурные свойства поля эпицентров путем рассмотрения простейших объектов - пар эпицентров-соседей. Для этого было необходимо выработать особую методику. Проблема в том, что наличие афтершоков и роев создает мощный искажающий эффект при любом исследовании пар событий. Другая трудность - это сильное преобладание направлений вдоль основной геологической оси изучаемого региона. Наличие таких предпочтительных направлений ожидаемо и представляет ограниченный интерес, поэтому их влияние следовало подавить. Используя специальные методики анализа, можно надеяться, что будут выявлены важные свойства внутренней геометрии поля эпицентров. Вообще говоря, геометрическую структуру сейсмичности следовало бы изучать в трех измерениях, однако из-за низкой точности глубин ограничились двумерной картиной.

Исследование угловой структуры эпицентровсоседей представляет интерес с нескольких точек зрения: 1) установления новых свойств статистической структуры наблюдаемого поля эпицентров,
2) изучения взаимодействия очагов землетрясений, 3) выявления сводных геометрических характеристик сетки разломов невысокого ранга. Описываемая работа была начата в 1974-1975 гг. с выявления в Камчатском каталоге цепочек, вполне аналогичных цепочкам по А.А. Лукку [Lukk, 1978], но была приостановлена оттого, что реальность многокомпонентных цепочек трудно доказать. Хотя изучать пары соседей - более примитивный подход, его использование дает больше возможностей для строгого анализа. С идейной стороны публикации группы А.А. Лукка имеют несомненный приоритет.

Структура работы следующая. Приведен базовый алгоритм построения гистограмм направлений, описаны его модификации, список параметров и их принятые значения. Охарактеризован исходный каталог. Описан ряд вариантов расчетов, и рассмотрены их результаты.

\section{2. МЕТОДИКА ПОСТРОЕНИЯ РОЗА-ДИАГРАММ ДЛЯ ВЫЯВЛЕНИЯ ПРЕДПОЧТИТЕЛЬНЫХ НАПРАВЛЕНИЙ}

\section{1. ОБщий подход}

Идея работы состоит в том, чтобы изучить статистику направлений векторов, соединяющих эпицентры землетрясений-соседей [Gusev, Palueva, 2016]. «Соседство» в пространстве определяется через максимально допустимое расстояние. Однако малые расстояния необходимо исключать, так как при ограниченной точности эпицентров направления коротких векторов могут быть грубо неверными. «Соседство» во времени можно определять как через максимально допустимое запаздывание, так и через максимально допустимую разность номеров $k_{2}$ в упорядоченном по времени каталоге. Использовали комбинацию двух этих подходов. Задание небольшого $k_{2}$ позволяет дополнительно подавить искажающий эффект группирования, так как не допускает формирования более $k_{2}$ пар с одним и тем же участником.

Статистику направлений изучали в пределах определенного периода времени и в пределах ограниченной области в плане. Для исключения влияния формы этой области на статистику направлений использовали круговую область. Эпицентры, попавшие в выделенную пространственно-временную область, составляют некий субкаталог. До выделения пар проводили подавление роев, то есть прореживание субкаталога в пространственновременной окрестности выраженных групп. При прореживании отбрасывались события с меньшими магнитудами. Хотя выше упоминались векторы, фактически изучали направления соответствую- 
щих отрезков. Для этого азимуты векторов приводили в диапазон 0-180, вычитая $180^{\circ}$, если необходимо. Эмпирически была обнаружена важная роль азимута простирания островной дуги $A z_{0}$ в статистике углов, поэтому основной анализ вели не непосредственно для азимутов направлений отрезков пар-соседей $A z$, а для условных азимутов $v=A z-A z_{0}$. Гистограмму $v$ назовем R-гистограммой.

Важный компонент алгоритма, как объяснено во Введении, - это подавление малоинтересного направления вдоль структуры островной дуги. При этом в качестве «фона» использовали статистику $v$ для пар «несоседей», для выделения которых применяли тот же алгоритм, но допустимый интервал времени определялся диапазоном 100-200 сут. Считалось, что сформированная таким образом гистограмма (Т-гистограмма или «нормализатор») отражает типичную геометрию пар эпицентров в чисто пространственном аспекте, без учета близости во времени. Требование пространственного соседства сохранялось. Деление значений R-гистограммы на значения «нормализатора» дает «нормализованную гистограмму» или N-гистограмму, которая не является гистограммой в собственном смысле.

Завершающий этап анализа - нахождение уровня значимости для гипотезы «R-гистограмма отличается от Т-гистограммы», или, что содержательно то же самое, «N-гистограмма отлична от постоянной». Для этого использовали обычный критерий $\chi^{2}$ Пирсона. При этом обнаружение значимости обосновывает лишь факт наличия неравномерности, то есть присутствия каких-то (не конкретизируемых) неслучайных лепестков на роза-диаграмме, представляющей $\mathrm{N}$-гистограмму. Статистическая проверка реальности индивидуальных лепестков, видимых на роза-диаграмме, в данной работе не выполнялась.

\section{2. АЛГОРИТМ ПОСТРОЕНИЯ ГИСТОГРАММ НАПРАВЛЕНИЙ (РОЗА-ДИАГРАММ)}

- Составление субкаталога по времени, месту, глубине и магнитуде; исключение гипоцентров с заведомо низкой точностью.

- Прореживание роев.

- Выделение в субкаталоге всех пар, допустимых по временному ограничению.

- Выделение среди выбранных пар, с учетом пространственного ограничения, именно пар соседей.

- Преобразование векторов пар в отрезки, нахождение азимутов $A z$ отрезков, расчет значений $v=A z-A z_{0}$ и приведение их в диапазон [0-180].
- Построение R-гистограммы для соседей.

- Построение Т-гистограммы.

- Расчет N-гистограммы.

- Определение уровня значимости для гипотезы «N-гистограмма отлична от постоянной».

Список параметров алгоритма включает следующие группы:

- Координаты центра $\lambda_{0}, \phi_{0}$ и радиус $R_{0}$ круговой области отбора эпицентров.

- Диапазоны отбора очагов для субкаталога: по времени $\left(t_{1}, t_{2}\right)$, магнитуде $M_{L}\left(M_{L 1}, M_{L 2}\right)$, глубине $\left(H_{1}, H_{2}\right)$.

- Параметры $N_{x} N_{y}, N_{t} K_{0}$ процедуры подавления групп.

- Параметры соседства: разрешенный диапазон $\left(D_{1}, D_{2}\right)$ значений длины векторов $\boldsymbol{r}$, разрешенный диапазон относительного запаздывания времени пар $\left(\Delta t_{1}, \Delta t_{2}\right)$, разрешенный диапазон разностей номеров компонент пары в субкаталоге $\left(k_{1}, k_{2}\right)$. Обычно, кроме особых случаев, $\Delta t_{1}=0, k_{1}=1$.

- Азимут отсчета углов $A z_{0}$, размер ячейки гистограммы углов $\Delta v$.

\section{3. ПРОЦЕДУРА ПРОРЕЖИВАНИЯ ГРУПП}

Каждый из многих членов плотной, локализованной группы эпицентров (например, каждый афтершок события с $M \approx 5)$ создает в комбинации с другим (фиксированным) подходящим эпицентром отдельную пару. Все такие пары несут одну и ту же информацию о геометрии поля эпицентров, и можно было бы учитывать любую одиночную пару из такой серии. Но избыточность информации - не самое важное; хуже то, что подобная серия пар нередко формирует лепесток роза-диаграммы, имеющий вполне фиктивный характер. Число тесных групп велико, поэтому подавление их влияния важная задача любого алгоритма анализа угловой структуры эпицентров.

Систематические алгоритмы выявления групп были предложены в [Gusev, 1971; Molchan, Dmitrieva, 1991]. Их идея - выделить пространственно-временные сгустки поля эпицентров, маловероятные в «чисто случайном» каталоге. Сгустки обрабатываются в индивидуальном порядке и заменяются на одиночный эпицентр. Однако для изучения статистики направлений такая замена выглядит слишком радикальной стратегией. Предпочтительно иметь возможность снижать плотность эпицентров в области сгустков регулируемым образом. Для реализации такого принципа применили следующий алгоритм. 
Рассмотрим подкаталог, выбранный из параллелепипеда с размерами $L_{x}$ и $L_{y}$ по пространству. Разделим $L_{x}$ и $L_{y}$ на $N_{x}$ и $N_{y}$ одинаковых частей, соответственно, и проведем через точки деления плоскости, параллельные граням параллелепипеда. Вполне аналогичную процедуру проведем вдоль временной оси: длительность $T$ субкаталога разделим на $N_{t}$ одинаковых частей. Возникает простая трехмерная сетка из $N_{x} \cdot N_{y} \cdot N_{t}$ ячеек. Подсчитаем для этих ячеек числа заполнения $K_{i j k}$ точками каталога, т.е. построим 3D-гистограмму. Введем порог $K_{0}$ и рассмотрим каждую из ячеек с $K_{i j k} \geq K_{0}$. Считаем, что такие ячейки соответствуют группам или их частям. В каждой такой ячейке рассматриваем список событий, упорядоченный по магнитуде, и отбрасываем слабые события, так что остается $K_{0}$ наиболее сильных. Данный алгоритм подавляет эффекты группирования, причем степень подавления, при определенном варианте задания набора $N_{x}, N_{y}, N_{t}$, определяется выбором $K_{0}$. Принятые далее значения параметров $N_{x}, N_{y}, N_{t}$ и $K_{0}$ имеют пробный характер и заметно улучшают результаты в сравнении с исходным каталогом. Оптимизация параметров в алгоритме прореживания роев оставлена на будущее.

\section{4. ДЕТАЛИ АЛГОРИТМА}

Выбор диапазона $\left(D_{1}, D_{2}\right)$ значений длин векторов в существенной мере определяется точностью гипоцентров $E$. Чтобы оценки азимутов имели смысл, значения $D_{1}$ должны превышать $E$ в несколько раз. Значение $D_{2}$ должно быть заметно ниже, чем $R_{0}$, чтобы ослабить нежелательное влияние границ рабочей области. Ряд параметров приходится выбирать на основе компромисса. Важен выбор $\Delta t_{2}$ : при малых $\Delta t_{2}$ объем статистики мал и результаты ненадежны; при больших $\Delta t_{2}$ растет объем чисто случайных пар и результаты зашумляются. Рост объема статистики может быть получен увеличением длительности рабочего каталога, $t_{2}-t_{1}$, но при этом ухудшается возможность изучения временных вариаций.

\section{3. РАБОЧИЙ КАТАЛОГ, ВЫБОР ПАРАМЕТРОВ РАСЧЕТОВ}

\section{1. ВЫБОР ОБЛАСТИ АНАЛИЗА, ОТБОР ОЧАГОВ}

Исходный региональный каталог Камчатки получен в работах ИФЗ РАН, ИВ ДВО РАН под руководством С.А. Федотова; ОМСП ГС РАН, КФ ГС РАН под руководством Е.И. Гордеева, В.Н. Чеброва; каталог доступен по URL http://www.emsd.ru/sdis/ earthquake/catalogue/catalogue.php. Расчет эпицентров выполнялся по программе ГИПО А.А. Гусева.

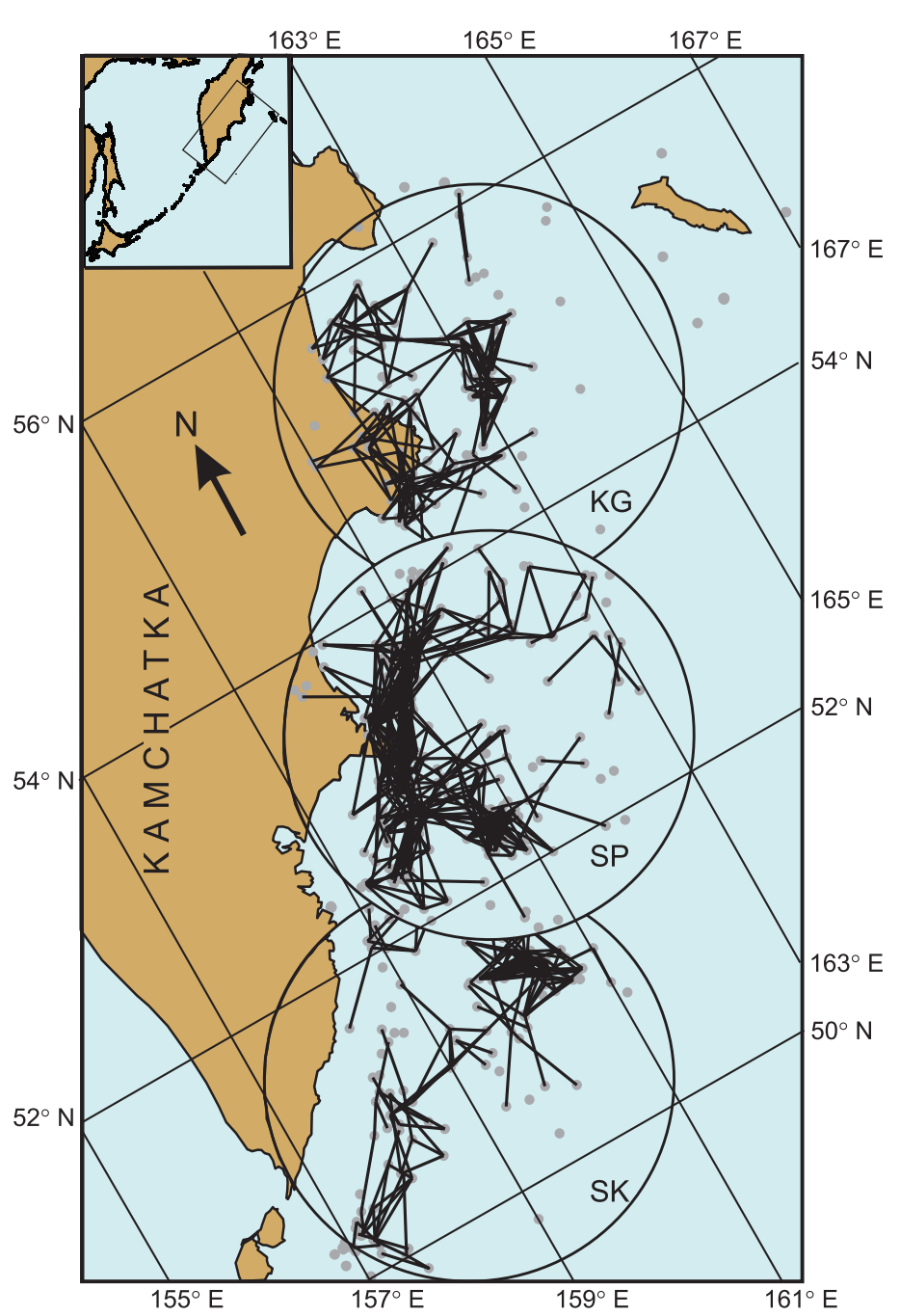

Рис. 1. Примеры расположения пар эпицентров для трех изученных кругов - SP, SK и KG (1962 г.). Параметры выделения пар следующие: $\left(\Delta t_{1} \Delta t_{2}\right)=0-15$ сут, $\left(D_{1} D_{2}\right)=15-60$ км, $K^{\Phi 68}=8.5-11.4\left(M_{L}=3.5-5.0\right)$. Расположение района работ - на врезке.

Fig. 1. Locations of pairs of epicenters in the three studied circles (SP, SK and KG) (1962). Selection parameters: $\left(\Delta t_{1} \quad \Delta t_{2}\right)=0-15$ days, $\left(D_{1} D_{2}\right)=15-60 \mathrm{~km}, K^{\Phi 68}=8.5-11.4$ $\left(M_{L}=3.5-5.0\right)$. The geographical position of the region is shown in the insert.

Полная длительность изучавшейся части исходного каталога - с 1962 по 2010 г. Области анализа (рис. 1) выбирались в виде кругов с $R_{0}=150$ км и располагались вдоль структур островной дуги. Изучали три круга, получившие коды SK (Южная Камчатка), SP (район Шипунского п-ва) и KG (район Камчатского залива). Допускалось небольшое перекрытие кругов. На этапе подавления групп обрабатывался квадрат, для которого круг является вписанным.

Для обеспечения приемлемой точности гистограмм каталог разбивался на периоды длиной 
Т а б л и ц а 1. Интервалы времени - «десятилетки» и их коды

$\mathrm{T}$ a b l e 1. Time intervals - decades and their codes

\begin{tabular}{lll}
\hline Период & Код & Примечание \\
\hline $1962-1971.11 .24$ & «65» & $\begin{array}{l}\text { два землетрясения с } M \geq 7.6 \text { с датами 21.11.1971 и } 15.12 .1971 \text { после } \\
\text { конца указанного периода }\end{array}$ \\
$1972-1980$ & «75» & \\
$1981-1990$ & «85» & землетрясение 5.12.1997 с $M=7.9$ после окончания указанного периода \\
$1991-1997.12 .04$ & «95» & \\
\hline
\end{tabular}

около 10 лет, охарактеризованные в табл. 1. Диапазон $M_{L}$ составлял всегда 3.5-5.0, при этом полнота субкаталога на нижнем пороге обеспечивается везде, кроме южной части круга SK. Для задания локальной магнитуды $M_{L}$ использовали имеющиеся в каталоге энергетические классы $K^{\Phi 68}$, при

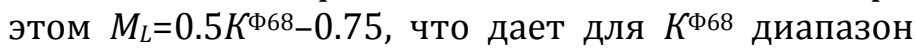
(8.5-11.4). Относительная точность локализации эпицентров неоднородна, ее оценки составляют 5-10 км вблизи побережья и до 25 км с океанской стороны зоны субдукции. Очаги с оценкой точности в каталоге более \pm 15 км исключали. Изучали мелкофокусные очаги, с глубинами в диапазоне 0-50 км. Азимут простирания структуры островной дуги Камчатки принимали $A z_{0}=37^{\circ}$.

\section{2. ПАРАМЕТРЫ ПОСТРОЕНИЯ И АНАЛИЗА ГИСТОГРАММ}

В основных расчетах принимали $N_{x}=10, N_{y}=10$, $N_{t}=10 ; K_{0}=10 ; D_{1}=15$ км, $D_{2}=60$ км; $\Delta t_{1}=0, \Delta t_{2}=0.5$ сут; $k_{1}=1, k_{2}=3 ; \Delta v=10^{\circ}$. Отклонения от этой схемы оговорены. При расчете гистограммы-нормализатора принимали $\Delta t_{1}=100$ сут, $\Delta t_{2}=150$ сут.

\section{4. РЕЗУЛЬТАТЫ РАСЧЕТОВ}

На рис. 1 приведена иллюстрация картины векторов пар соседей за годовой период при $\Delta t_{2}=15$ сут. Видно, что векторы, образуемые парами эпицентров-соседей, направлены не вполне случайным образом, иногда можно заметить группы субпараллельных отрезков. Но эта картина - чисто качественная, и на ее основе трудно сформулировать выводы, которые можно было бы аккуратно проверить.

На рис. 2 приведена иллюстрация к процедуре прореживания роев. Как описано выше, процедура предусматривает построение трехмерной $(\mathrm{X} \times \mathrm{Y} \times \mathrm{T})$ гистограммы размещения событий $K_{i j k}$. Распределение значений чисел заполнения $K_{i j k}$, видно на одномерной гистограмме рис. 2 , a. Поскольку диапа- зон значений $K_{i j k}$ очень велик, для графической ясности на рис. 2, $a$, использованы клетки, расположенные логарифмически равномерно по абсциссе. Помечена часть этой гистограммы, соответствующая «плотно заполненным» ячейкам гистограммы $K_{i j k}$. «Плотно заполненными» считаются ячейки с числом событий $K_{i j k}$ более $K_{0}$; в использованной настройке алгоритма $K_{0}=10$. В каждой такой ячейке среди попавших в нее событий выбираются и удаляются из каталога наиболее слабые; сохраняется $K_{0}$ событий. Из полного числа 1000 ячеек гистограммы $K_{i j k} 560$ - пустые и не отображены на гистограмме рис. 2, а. Из отображенных 460 непустых ячеек 42 содержат $K=11$ событий и более, они составляют незатененные столбики.

На рис. 2, б (не гистограмма!), для каждого столбика графика «а» отображено суммарное число событий $m$, попавших во все ячейки, отнесенные к этому столбику. Из полного числа 1549 событий 573 попадают в «плотно заполненные» ячейки с $K \geq 11$ и более (видны суммарно как незатененные столбики на графике «а»). Далее выполняется прореживание: отбрасываются 153 события, слабейшие в каждой клетке.

На рис. 3 приведены некоторые результаты опробования описанного алгоритма. Иллюстрируется выбор параметра $\Delta t_{2}$. Приводятся R-гистограммы за периоды «65» и «85» для круга SP. Гистограммы даны как в обычном формате, так и в виде розадиаграмм. Строго говоря, эти два представления дублируют друг друга, но для глаза дают качественно разную информацию. Параллельно даны результаты для вариантов $\Delta t_{2}=0.5$ сут и $\Delta t_{2}=5$ сут. На глаз распределение направлений отличается от равномерного. При проверке значимости за исходную (нулевую) гипотезу принимали равномерное распределение. На графике приводится оценка уровня значимости $Q$, которая менее $0.1 \%$ для обоих вариантов с $\Delta t_{2}=5$ сут и в одном случае для варианта с $\Delta t_{2}=0.5$ сут. В другом таком случае равномерность не опровергается. Причина противоречий с глазомерной оценкой в том, что числа заполнения клеток при $\Delta t_{2}=0.5$ сут невелики (в среднем 
A.A. Gusev, A.A. Palueva: First results on the direction statistics of pairs of epicenters...
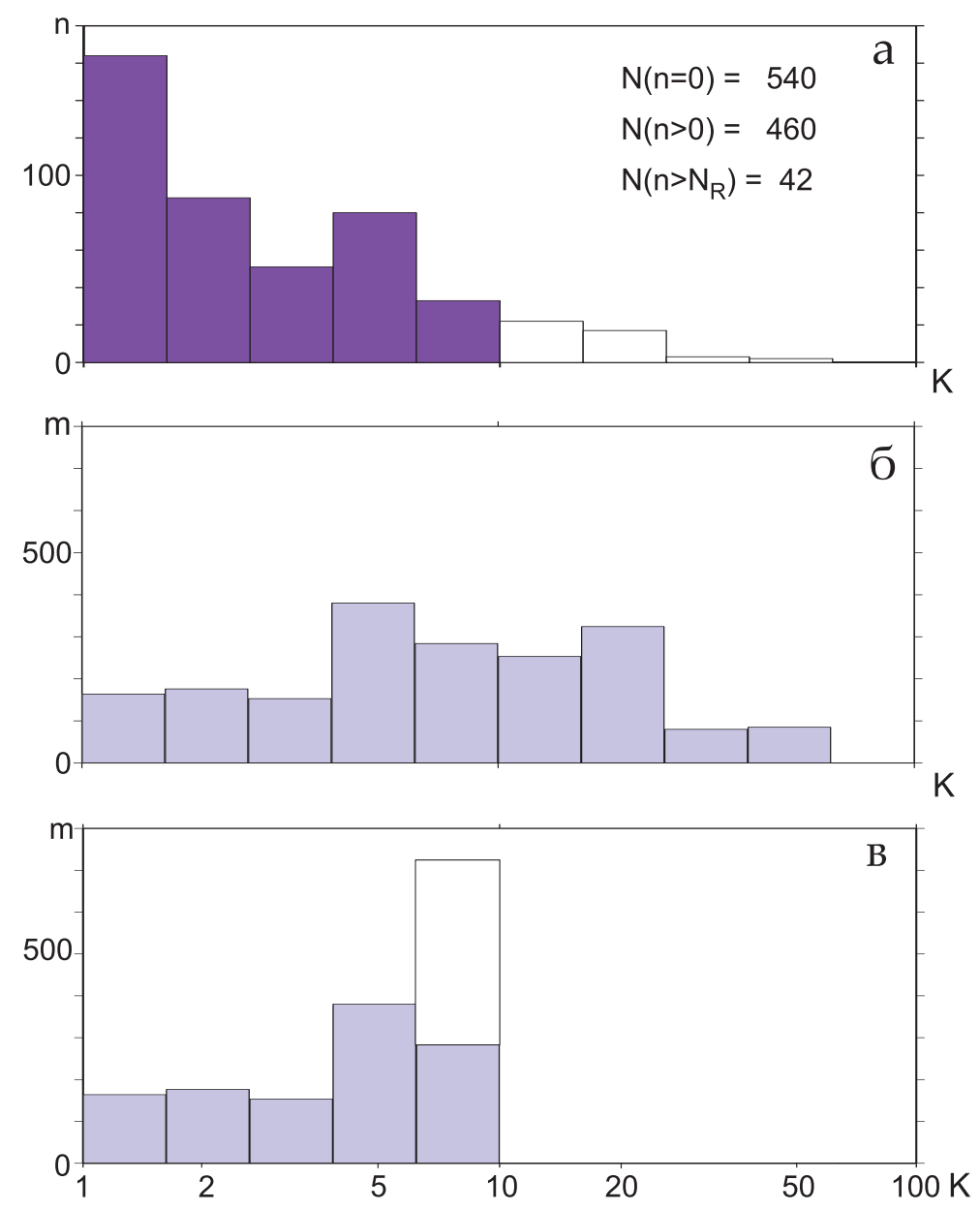

Рис. 2. Иллюстрация к процедуре прореживания роев.

Выбрасываются из каталога наиболее слабые события из тех, которые попали в «плотно заполненные» клетки трехмерной $(\mathrm{X} \times \mathrm{Y} \times \mathrm{T})$ гистограммы. «Плотно заполненными» считаются клетки с числом событий $K_{i j k}$ более $K_{0} . a-$ распределение ячеек трехмерной гистограммы по числу $K$ событий в клетках, для данных района KG за период 1981-1990 гг. Столбики гистограммы (значения $n$ ) получены суммированием числа клеток с разными $K$ в пределах заданных диапазонов $K$, границы которых образуют ло-

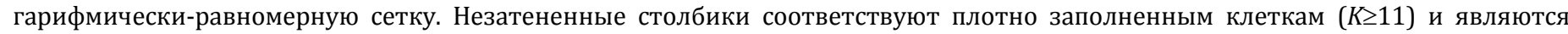
объектами прореживания; б - суммарные числа событий $m$, попавших во все ячейки, отнесенные к определенному столбику гистограммы «а»; приведено исходное состояние до прореживания; в - аналог графика «б» после прореживания. После прореживания число клеток с $K=10$ искусственно выросло, что отображено в виде незатененной добавки к самому правому столбику.

Fig. 2. Illustration of the swarms decimation procedure.

From the earthquake catalogue, we delete the weakest of those seismic events that fall into the 'densely filled-in' cells of the 3D $(\mathrm{X} \times \mathrm{Y} \times \mathrm{T})$ histogram. A cell is considered 'densely filled-in' if the number of events $K_{i j k}$ is above $K_{0} . a$ - distribution of cells of the 3D histogram by the number of events, $K$, in the cells for the data on circle KG from 1981 to 1990 . Histogram bars (values $n$ ) are obtained by summing the number of cells with different values of $K$ within the specified ranges of $K$, the boundaries of which form a logarithmically uniform grid. Unshaded bars correspond to densely filled-in cells $(K \geq 11)$ and subject to decimation; $\sigma$ - numbers of events $m$, which fall in all the cells, that refer to a specific column of the histogram in Fig. 2, $a$; the initial state before the decimation procedure is shown; 8 - the analogue of the plot Fig. 2, 6, after decimation. The number of cells with $K=10$ is artificially increased after decimation, which is shown by the unshaded increment to the rightmost column.

около 10) и наблюдаемые отклонения вполне могут быть сформированы за счет случайных флуктуаций. Для случая $\Delta t_{2}=5$ сут визуально отклонения выражены слабее, однако при увеличенных числах заполнения (в среднем около 50) формирование даже таких отклонений за счет случайных флуктуаций маловероятно. Однако в плане задач исследования выявление резких отклонений от равномер- ности представляет основной интерес, поэтому было принято решение использовать в работе именно значение $\Delta t_{2}=0.5$ сут. Такое решение оправдывается редкостью возникновения случаев, когда $Q$ более $0.1 \%$.

На гистограммах для $\Delta t_{2}=5$ сут резко проявилось направление $A z_{0}$, видимое как всплески вблизи $0^{\circ}$ и $180^{\circ}$. Выявление этого направления не имеет 

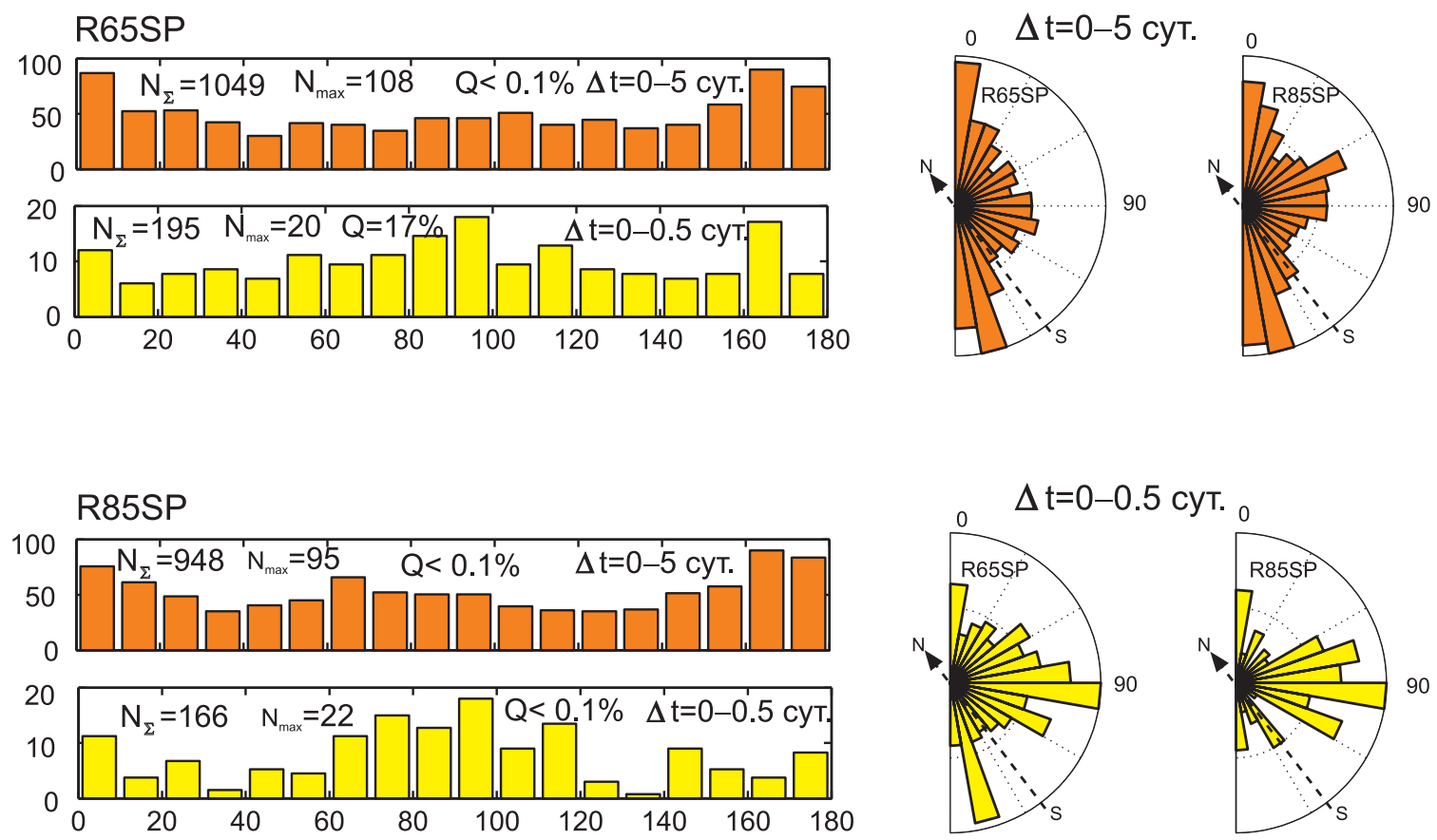

Рис. 3. Примеры гистограмм направлений векторов пар, определяемых через параметр $v$ (слева) и соответствующих роза-диаграмм (справа), для круга SP, для двух периодов - «65» и «85» и для двух вариантов параметра $\Delta t_{2}-5$ и 0.5 сут.

Fig. 3. Direction histograms of the vectors of pairs defined via parameter $v$ (left), and the corresponding rose diagrams (right) for SP circle. Two periods, 65 and 85. Two variants of parameter $\Delta t_{2}, 5$ and 0.5 days.

новизны, но сам факт достоин упоминания. На гистограммах для $\Delta t_{2}=0.5$ сут данное направление заметно ослабевает, что дает дополнительные основания для выбора именно этого значения $\Delta t_{2}$ в основной части работы.

На рис. 4 приведены результаты основных расчетов по кругу SK. Показаны R-гистограммы за пять десятилеток, Т-гистограмма (сумммарная за 50 лет) и пять N-гистограмм. Видно наличие в $\mathrm{R}$-гистограммах преимущественного направления $v$ вблизи $0^{\circ}$ и $180^{\circ}$, оно, как и следует ожидать, особенно хорошо видно на $\mathrm{N}$-гистограммах. Ha R- и $\mathrm{N}$-гистограммах заметны всплески, соответствующие лепесткам роза-диаграмм.

Особенно заметно наличие в $\mathrm{N}$-гистограммах преимущественного направления $v \approx 90^{\circ}$. Оно очень четко выражено для десятилеток «65» и «05»и хорошо заметно для десятилеток «75» и «85». Для десятилетки «95» наиболее мощный лепесток уходит на $v=105^{\circ}$, а гистограмма приближается к равномерной. Возможно, данная особенность связана с тем фактом, что в 1992-1993 гг. произошли наиболее сильные за 50 лет землетрясения в круге SK $\left(M_{w}\right.$ до 7.5), причем период их афтершоков не исключался из субкаталога.

Имеются также заметные, но менее устойчивые во времени лепестки, например по $v=145^{\circ}$ для пе- риодов «85» и «05», по $v=65^{\circ}$ для тех же периодов, $v=25^{\circ}$ и $155^{\circ}$ для периода «75». В целом, видно формирование довольно четких индивидуальных лепестков. Этот материал обобщен в табл. 2. Имеются также явные временные вариации гистограмм и роза-диаграмм.

На рис. 5 приводятся результаты аналогичных расчетов по кругу SP. Снова четко выражены временные вариации. Преимущественное направление вблизи $v=90^{\circ}$, имевшее место для круга SK, снова обнаруживается для круга SP. Другие выраженные лепестки: по $v=165^{\circ}$ для периодов «65» и «95», $v=135^{\circ}$ для периода «95».

На рис. 6 приводятся такие же результаты для круга KG. В этом случае картина иная: направление $v=90^{\circ}$ не выражено, и в то же время имеется несколько менее четкое преимущественное направление $v \approx 70^{\circ}$. Любопытно, что этот разворот примерно согласуется с разворотом структур островной дуги вблизи Кроноцкого п-ова от азимута около $35^{\circ}$ к азимуту около $10-15^{\circ}$, так что направление данного лепестка сохраняет свое поперечное расположение относительно простирания структур островной дуги.

Интересно увидеть, как выраженные лепестки роза-диаграмм проявляют себя непосредственно на карте. На рис. 7 это выполнено для круга SP 
A.A. Gusev, A.A. Palueva: First results on the direction statistics of pairs of epicenters...

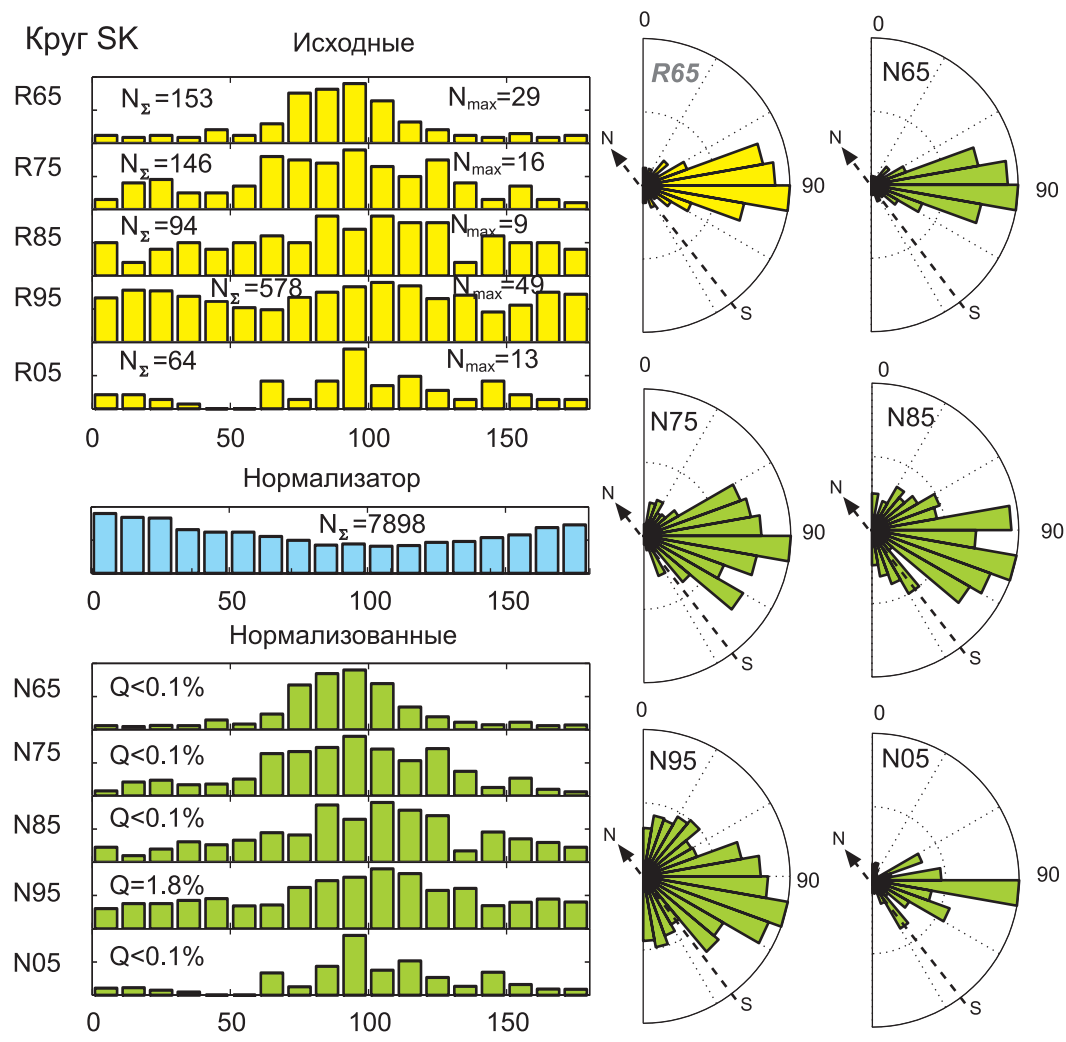

Рис. 4. Гистограммы направлений (слева) и соответствующие роза-диаграммы (справа) для круга SK, для пяти периодов.

Гистограммы и роза-диаграммы масштабированы, каждая к своему максимуму. Сверху вниз гистограммы образуют: группу из пяти исходных R-гистограмм (коды R65, R75 и т.д.), каждая для определенной десятилетки, T-гистограмму, использованную для нормализации, и далее группу из пяти нормализованных N-гистограмм (коды N65, N75 и т.д.). Роза-диаграммы соответствуют: верхняя левая - гистограмме R65, остальные - гистограммам N65-N05. Направление географического севера указано штриховой стрелкой.

Fig. 4. Histograms of directions (left), and the corresponding rose diagrams (right) for circle SK for five periods.

The histograms and rose diagrams are scaled, each to its maximum. Top to bottom histograms comprise a group of five initial R-histograms (codes R65, R75 etc.) for each specified decade, a T-histogram used for normalization, and then a group of five normalized N-histograms (codes N65, N75 etc.). The top left rose diagram corresponds to histogram R65. Other rose diagrams correspond to histograms N65-N05. True north is shown by the dash arrow.

Т а б л и ц а 2. Предпочтительные направления пар в разных кругах и разных периодах-десятилетках $\mathrm{T}$ a $\mathrm{b}$ l e 2. Preferred directions of the pairs in different circles and different decades

\begin{tabular}{|c|c|c|}
\hline Круг & Десятилетка & Предпочтительные направления* \\
\hline SK & $« 65 »$ & $95^{\circ}, 45^{\circ}, 155^{\circ}$ \\
\hline SK & «75» & $95^{\circ}, 25^{\circ}, 125^{\circ}, 155^{\circ}$ \\
\hline SK & «85» & $105^{\circ}, \mathbf{8 5}^{\circ}, 5^{\circ}, 35^{\circ}, 65^{\circ}, 145^{\circ}$ \\
\hline SK & $\ll 05 »$ & $95^{\circ}, 65^{\circ}, 115^{\circ}, 145^{\circ}$ \\
\hline SP & $« 65 »$ & $95^{\circ}, 5^{\circ}, 55^{\circ}, 115^{\circ}, 165^{\circ}$ \\
\hline SP & $\ll 75 »$ & $75^{\circ}, 5,115^{\circ}, 175$ \\
\hline SP & $« 05 »$ & $85^{\circ}, 45^{\circ}, 105^{\circ}$ \\
\hline KG & $« 65 »$ & $145^{\circ}, 65^{\circ}, 5^{\circ}, 35^{\circ}, 105^{\circ}$ \\
\hline KG & $\ll 75 »$ & $65^{\circ}, 15^{\circ}, 105^{\circ}, 145^{\circ}$ \\
\hline KG & «85» & $135^{\circ}, \mathbf{7 5}^{\circ}, 15^{\circ}, 115^{\circ}$ \\
\hline KG & $« 95 »$ & $\mathbf{7 5}^{\circ}, \mathbf{1 3 5}^{\circ}, 25^{\circ}, 105^{\circ}, 155^{\circ}, 175^{\circ}$ \\
\hline KG & $\ll 05 »$ & $\mathbf{7 5}^{\circ}, \mathbf{5 0}^{\circ}, 5^{\circ}, 120^{\circ}, 145^{\circ}, 165^{\circ}$ \\
\hline
\end{tabular}

П р и м е ч а н и е. ${ }^{*}$ - отсчет от луча с азимутом $37^{\circ}$. Полужирным выделены наиболее четкие направления.

$\mathrm{N}$ o t e. ${ }^{*}$ - angles with respect to the ray with azimuth $37^{\circ}$ taken as origin. Most expressed directions shown by bold face. 

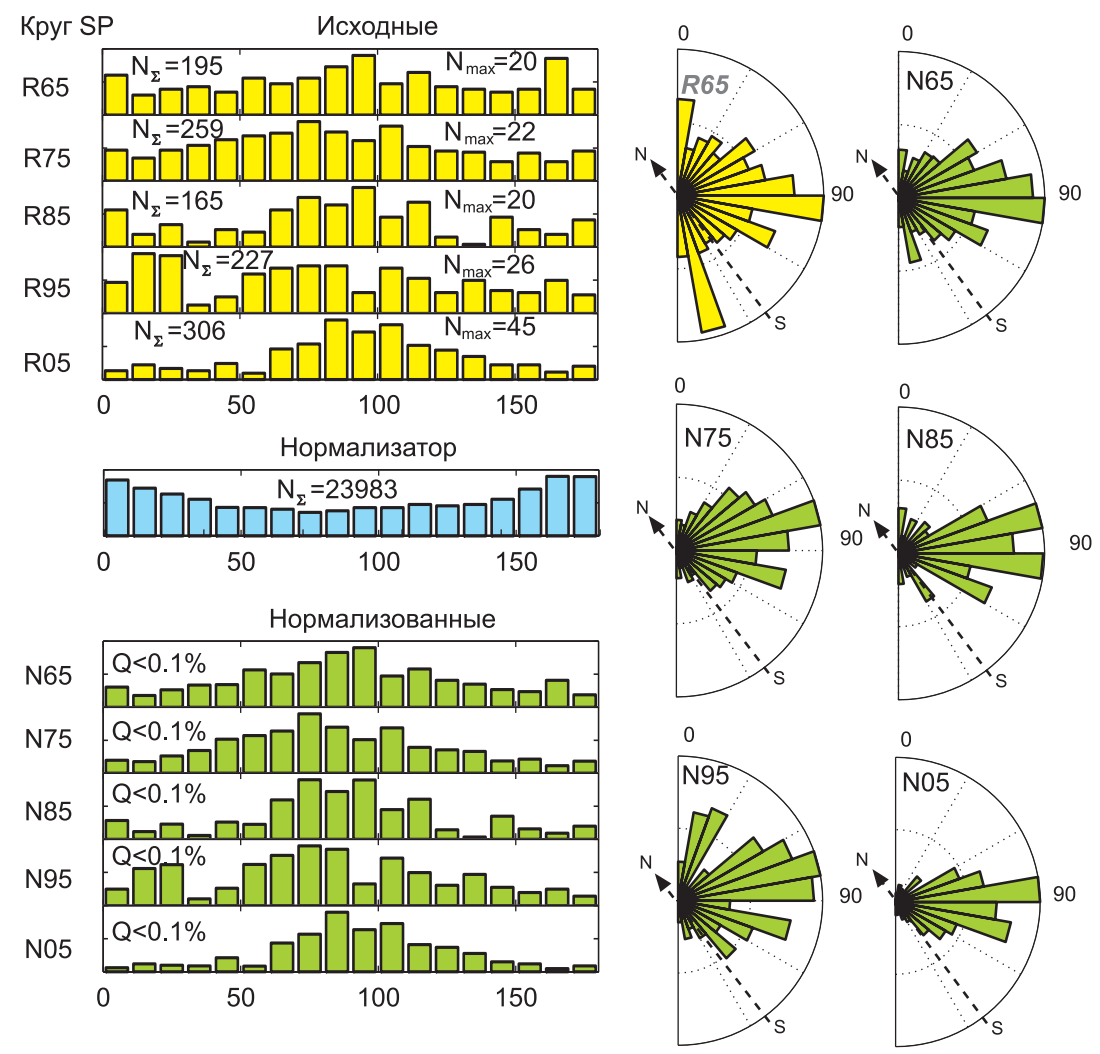

| Рис. 5. Аналог рис. 4 для круга SP.

Fig. 5. Analogue of Fig. 4 for SP circle.
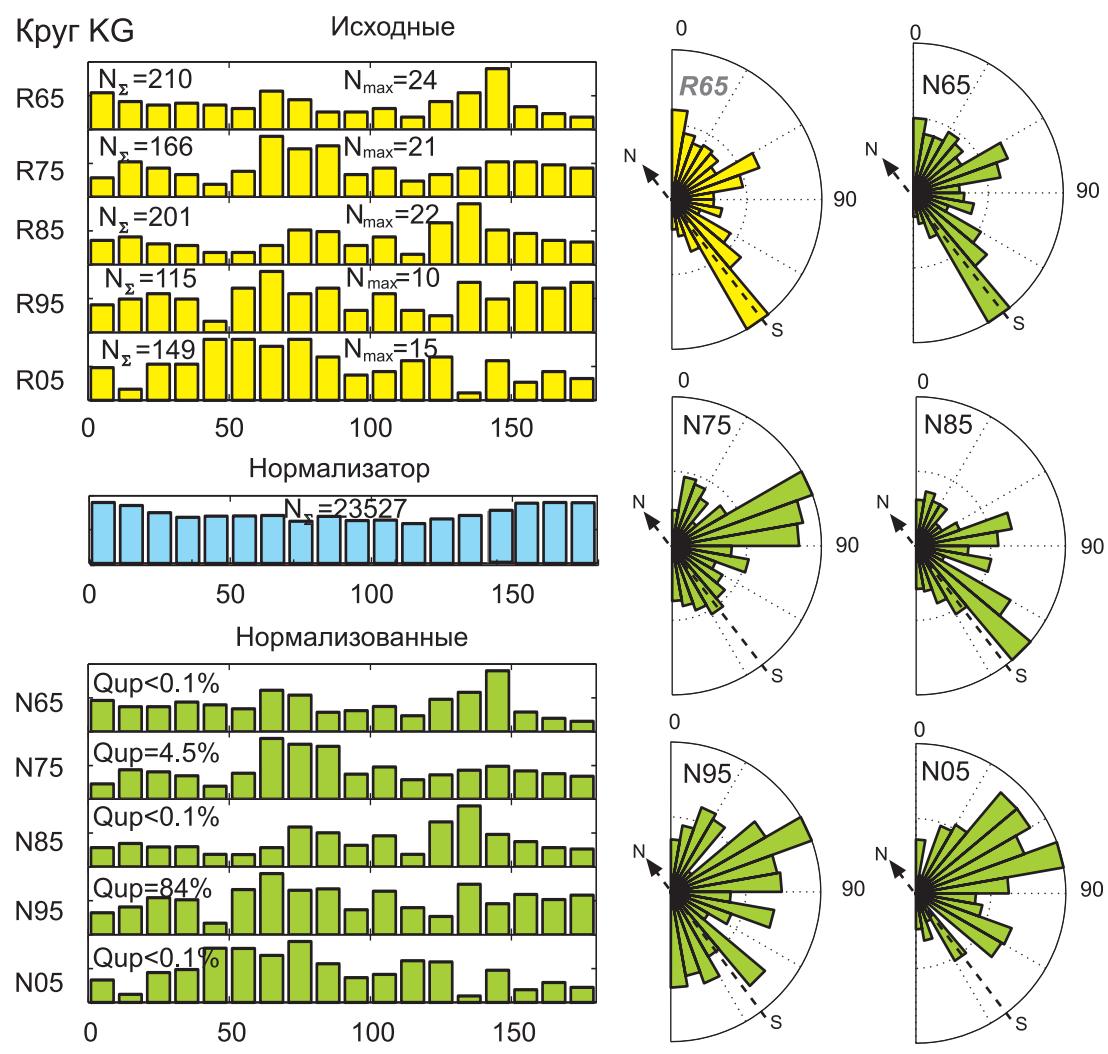

Рис. 6. Аналог рис. 4 для круга KG.

Fig. 6. Analogue of Fig. 4 for KG circle. 
за период «85». На каждой из двух карт выделено конкретное семейство субпараллельных векторов пар. Можно видеть два семейства, расположенные поперек и косо к структурам островной дуги. На рис. 8 выполнено аналогичное построение для круга KG.

Приведем сводку обнаруженных особенностей направлений пар эпицентров-соседей:

(1) отличие распределения направлений от равномерного по углу;

(2) наличие выраженных узких лепестков направлений;

(3) обострение лепестков при уменьшении интервала времени, принятого при отборе соседей;

(4) устойчивое появление выраженных лепестков с направлениями поперек структур островной дуги;

(5) грубое подобие роза-диаграмм соседних кругов SK и SP, аналогичных по морфологии островной дуге; отсутствие такого подобия для соседних кругов SP и SК с различиями в морфологии;

(6) заметные изменения роза-диаграмм от одного 10-летнего периода к другому;

(7) стабильность (или повторное появление) некоторых лепестков в течение длительных периодов времени.

\section{5. ОБСУЖДЕНИЕ}

Обнаруженная картина требует обсуждения в ряде аспектов.

(1) Возможные механизмы формирования неслучайных пар очагов-соседей с выраженными лепестками направленности. В качестве основной гипотезы мы предполагаем, что формирование пар определенного направления связано с субпараллельной («эшелонированной») системой активных разломов. Подобные системы хорошо известны и выделяются на разных масштабных уровнях. Обычно присутствуют две-три преобладающие системы; они разбивают среду на относительно жесткие блоки с субпараллельными контактами. Если бы по разлому происходило единое быстрое движение на изученных расстояниях 15-60 км, то возник бы очаг землетрясения с магнитудой 6.0-7.5. Формирование привязанных к разлому и связанных по времени пар слабых землетрясений должно иметь иную природу. Допустим, что вдоль разлома распространяется ненаблюдаемый импульс асейсмического скольжения, который активизирует отдельные квазихрупкие (velocity-weakening) участки этого разлома, наблюдаемые как слабые землетрясения. В этом случае вполне возможны и активизация структур с размерами в десятки километров, и синхронизация событий на таких удалениях. В

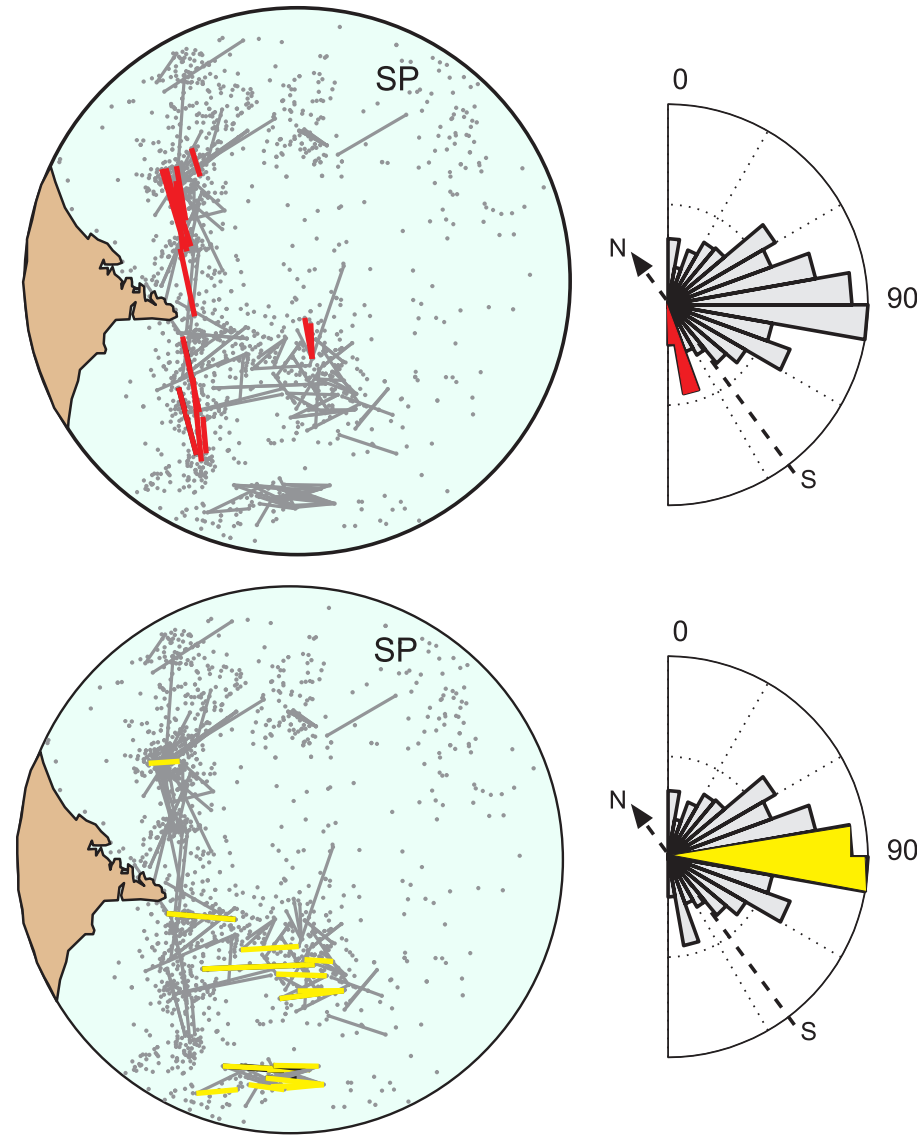

Рис. 7. Два варианта карты круга SP (слева) для периода «85».

На каждом варианте выделены цветом отрезки-пары определенного направления: для верхнего круга $v=160-170^{\circ}$, для нижнего круга $v=80-100^{\circ}$, в остальном карты идентичны. Отрезки-пары других направлений и эпицентры - серые. Выделенные направления отображены в виде цветных секторов на нормализованной роза-диаграмме справа от каждой карты.

Fig. 7. Two variants of the SP circle map (left) for period 85.

In each variant, segments-pairs of specified direction are highlighted: $v=160-170^{\circ}$ for the upper circle, and $v=80-100^{\circ}$ for the lower circle. In the rest, the maps are identical. Segments-pairs of other directions and epicentres are coloured in gray. The directions are shown as colored sectors in the normalized rose diagram to the right of each map.

сущности, речь идет о миграции. Такое объяснение выглядит наиболее правдоподобным. Возникновение лепестков связывается в этом случае с тем, что обсуждаемые асейсмические разломы - это компоненты упомянутой неслучайной сетки субпараллельных разломов.

Альтернативное объяснение можно выдвинуть на основе другой идеи. Можно думать, что один очаг влияет на другой через статическое упругое поле либо через динамический эффект бегущей 

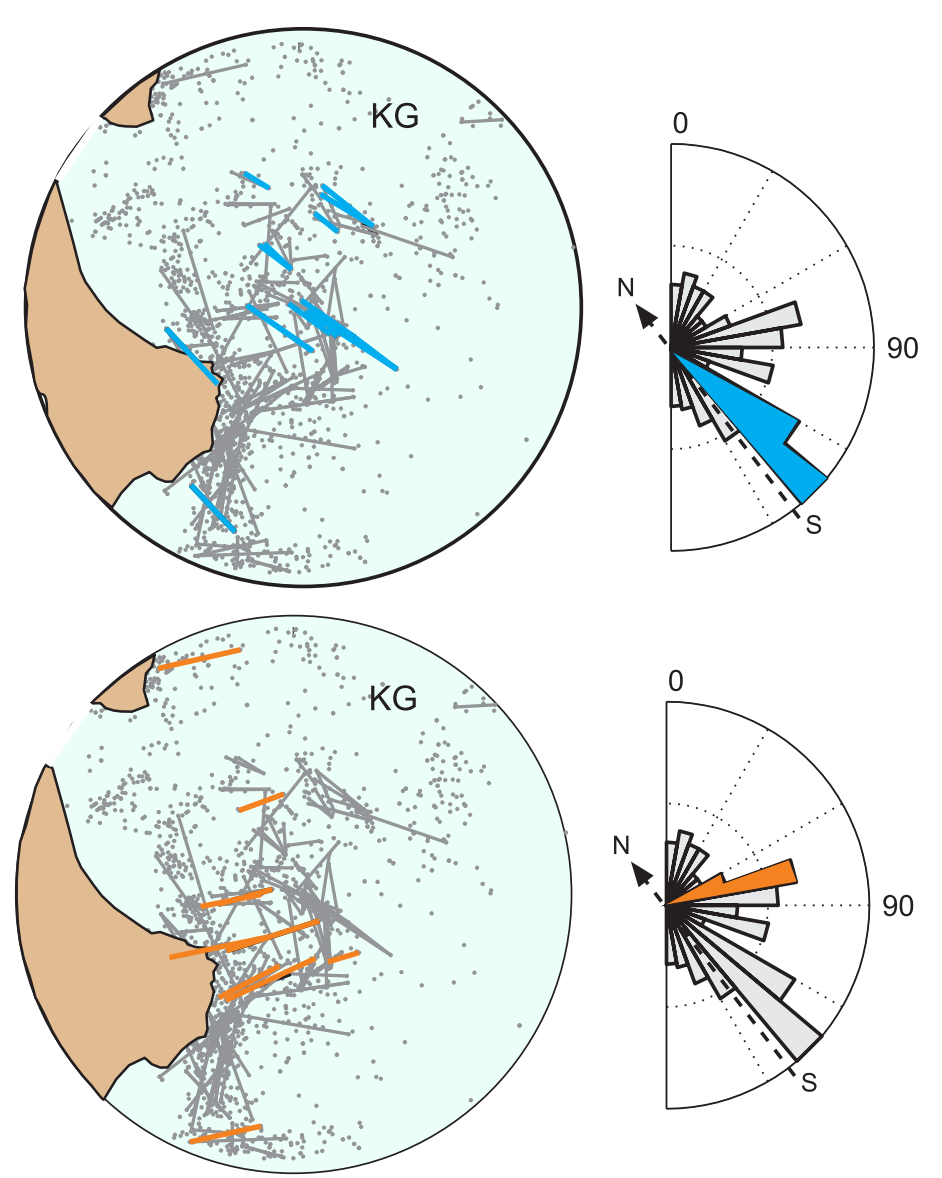

Рис. 8. Аналог рис. 7 для круга KG (слева) для периода «85». Выделенные направления: для верхнего круга $v=60-100^{\circ}$, для нижнего круга $v=120-150^{\circ}$.

Fig. 8. Analogue of Fig. 7 for circle KG (left) for period 85. Directions: $v=60-100^{\circ}$ for the upper circle, and $v=120-$ $150^{\circ}$ for the lower circle.

сейсмической волны («triggering»). Это явление повышает вероятность появления второго эпицентра в окрестности первого, причем этот второй эпицентр возникает там, где имеется ослабленное место - молчащий активный разлом. Такая картина также возможна, но быстрый спад напряжений с удалением от первого очага делает такое объяснение менее убедительным.

(2) Природа поля напряжений, способного активизировать субпараллельные линеаменты определенных направлений. В области субдукционного меганадвига (круги SK и SP) преобладающее напряжение - сжатие поперек структур дуги и вдоль вектора взаимного движения плит, примерно по $A z \approx 130^{\circ}\left(v \approx 90^{\circ}\right)$. Если исходить из теории Андерсона [Scholz, 2002, гл. 3], при близгоризонтальном максимальном главном напряжении сжатия можно ожидать следующие варианты разломообразования: (a) сдвиги с углом простирания $\pm 30-45^{\circ}$ к оси сжатия. Подобные направления имеются, но не преобладают;

(б) взбросы с углом простирания порядка $90^{\circ} \mathrm{\kappa}$ оси сжатия. Такие направления $\left(v \approx 0^{\circ}\right)$ проявлены широко, считаются неинтересными и подавлялись при нормализации.

Однако наиболее четко в кругах SK и SP показывает себя поперечное структуре и параллельное оси сжатия направление $v=90^{\circ}$. Этой четко выраженной тенденции нет явных причин. Объяснить такую геометрию можно через трещины отрыва, которые обычно располагаются вдоль оси сжатия. При этом для литосферы на глубинах в основном 15-35 км такое объяснение выглядит экзотически. Оно реализуемо, только если допустить полную компенсацию литостатического давления давлением порового флюида. Но следует заметить, что такую или чуть меньшую компенсацию приходится предполагать и просто для объяснения существования сейсмичности на этих глубинах, так что выдвигаемая гипотеза не выглядит вовсе неправдоподобной. В целом, интерпретацию полученных направлений в терминах ориентации вероятных разрывов в приблизительно известном поле напряжений провести не удается.

И эта ситуация не уникальна. А.А. Лукк и И.В. Турчанинов [Lukk, Turchaninov, 1998] выявили предпочтительные направления цепочек для Гарма. Таких направлений два: вдоль ориентировки основных горных хребтов района $\left(A z \approx 75^{\circ}\right)$ и по поперечному к ней направлению $A z \approx 165^{\circ}$. Имеются также менее четкие лепестки с $A z \approx 140^{\circ}$ и $50^{\circ}$. Если за начало отсчета углов, по аналогии с нашим подходом, взять направление главных структур (хребтов), лепестки из этой работы дадут направления: основные около $v=0^{\circ}$ и $90^{\circ}$, второстепенные около $v=50^{\circ}$ и $150^{\circ}$, что аналогично нашим результатам. Более того, как установили Ю.Л. Ребецкий и P.С. Алексеев [Rebetsky, Alekseev, 2014], для района Гарма следует ожидать направление максимального главного напряжения сжатия по $A z \approx 160^{\circ}$, т.e. практически точно поперек оси горной системы, в полной аналогии с ситуацией на Камчатке. Таким образом, загадочное преимущественное направление поперек оси структур и вдоль направления сжатия обнаруживается в двух тектонически и геодинамически различных обстановках.

Картина для круга KG менее определенная. Здесь структура островной дуги поворачивает к северу и направление субдукции становится косым по отношению к нормали к структурам. В то же время ориентировка оси сжатия меняется в небольшой степени. Тот наблюдаемый факт, что розы направлений здесь более сложно устроены, чем в двух южных кругах, качественно согласуется с бо- 
лее сложной геометрией активных структур в области стыка двух островных дуг.

(3) Изменчивость предпочтительных направлений во времени. Изучаемое явление представляет интерес как возможный инструмент мониторинга деформационных процессов в литосфере. А.А. Лукк и И.В. Турчанинов [Lukk, Turchaninov, 1998] наблюдали существенную изменчивость предпочтительных ориентировок и геометрии цепочек во времени; наши результаты имеют аналогичный характер. Можно сделать общий вывод: пары или цепочки соседей не только выявляют глубинную геометрическую структуру малоизученных живых разломов литосферы невысокого ранга, но также позволяют наблюдать за быстро меняющимися направлениями движений по этим разломам. При взгляде на исходное поле эпицентров геометрия разломов невидима, а динамика движений по ним скрыта от наблюдения.

\section{6. ЗАКЛЮЧЕНИЕ}

Разработана новая методика выявления по каталогу слабых землетрясений региона основных направлений движений по вторичным разломам и субпараллельным системам таких разломов. Подобные направления систем вторичных разломов определены для трех участков зоны субдукции на Камчатке. Обнаружены выраженные вариации данных направлений во времени. Описанный подход имеет определенные перспективы применения для слежения за активными процессами в литосфере.

\section{7. ЛИTEPATУPA / REFERENCES}

Amorese D., Lagarde J.L., Laville E., 1999. A point pattern analysis of the distribution of earthquakes in Normandy (France). Bulletin of the Seismological Society of America 89 (3), 742-749.

Gusev A.A., 1971. The nomogram for the selection of earthquake groups. Geologiya i Geofizika (Russian Geology and Geophysics) (3), 36-43 (in Russian) [Гусев А.А. Номограмма для выделения групп землетрясений // Геология и геофизика. 1971. № 3. С. 36-43].

Gusev A.A., Palueva A.A., 2016. Preliminary results from the statistic study of directions for pairs of neighboring earthquake epicenters in Kamchatka. In: Volcanism and related processes. Proceedings of the 19th Annual regional conference dedicated to Volcanologists Day. IVS FEB RAS, Petropavlovsk-Kamchatsky, p. 180-189 (in Russian) [Гусев A.A., Палуева A.A. Предварительные результаты изучения статистики направлений для пар эпицентров землетрясений-соседей на Камчатке // Вулканизм и связанные с ним процессы: Материалы XIX ежегодной региональной научной конференции, посвященной Дню вулканолога. Петропавловск-Камчатский: ИВиС ДВО РАН, 2016. С. 180-189].

Jones R.H., Stewart R.C., 1997. A method for determining significant structures in a cloud of earthquakes. Journal of Geophysical Research: Solid Earth 102 (B4), 8245-8254. http://dx.doi.org/10.1029/96JB03739.

Kostrov B.V., 1974. Seismic moment, energy of earthquakes, and seismic flow of rock masses. Izvestiya AN SSSR, seriya Fizika Zemli (Izvestiya, Physics of the Solid Earth) (1), 23-40 (in Russian) [Костров Б.В. Сейсмический момент, энергия землетрясений и сейсмическое течение горных масс // Известия АН СССР, серия Физика Земли. 1974. № 1. С. 23-40].

Kostrov B.V., 1975. Mechanics of Tectonic Earthquake Source. Nauka, Moscow, 176 p. (in Russian) [Koстров Б.B. Механика очага тектонического землетрясения. М.: Наука, 1975. 176 с.]

Lukk A.A., 1978. Spatio-temporal sequences of weak earthquakes in the Garm region. Izvestiya AN SSSR, seriya Fizika Zemli (Izvestiya, Physics of the Solid Earth) (2), 25-37 (in Russian) [Лукк А.А. Пространственно-временные последовательности слабых землетрясений Гармского района // Известия АН СССР, серия Физика Земли. 1978. № 2. С. 25-37].

Lukk A.A., Turchaninov I.V., 1998. Identification of linear earthquake epicenter sequences in the seismic field of the Garm region. Izvestiya, Physics of the Solid Earth 34 (10), 787-804.

Mogi K., 1968. Sequential occurrences of recent great earthquakes. Journal of Physics of the Earth 16 (1), 30-36. http://dx.doi.org/10.4294/jpe1952.16.30.

Molchan G.M., Dmitrieva O.E., 1991. Identification of aftershocks: an overview and new approaches. In: I.N. KeilisBorok, A.L. Levshin (Eds.), Modern methods of seismic data processing. Computational Seismology, vol. 24. Nauka, Moscow, p. 19-50 (in Russian) [Молчан Г.М., Дмитриева О.Е. Идентификация афтершоков: обзор и новые подходы // Современные методы обработки сейсмологических данных / Ред. В.И. Кейлис-Борок, А.Л. Левшин. Вычислительная сейсмология. Вып. 24. М.: Наука, 1991. С. 19-50].

Ouillon G., Ducorbier C., Sornette D., 2008. Automatic reconstruction of fault networks from seismicity catalogs: Three-dimensional optimal anisotropic dynamic clustering. Journal of Geophysical Research: Solid Earth 113 (B1), B01306. http://dx.doi.org/10.1029/2007JB005032. 
Rebetsky Yu.L., Alekseev R.S., 2014. The field of recent tectonic stresses in Central and South-Eastern Asia. Geodynamics \& Tectonophysics 5 (1), 257-290 (in Russian) [Ребецкий Ю.Л., Алексеев Р.С. Поле современных тектонических напряжений Средней и Юго-Восточной Азии // Геодинамика и тектонофизика. 2014. Т. 5. № 1. С. 257-290]. http://dx.doi.org/10.5800/GT-2014-5-1-0127.

Richter C.F., 1958. Elementary Seismology. W.H. Freeman and Co., San Francisco, 768 р. [Русский перевод: Рихтер Ч. Элементарная сейсмология. М.: Изд-во иностранной литературы, 1963. 670 c.].

Scholz C.H., 2002. The Mechanics of Earthquakes and Faulting. Second edition. Cambridge University Press, Cambridge, $471 \mathrm{p}$.

Shebalin P.N., 2005. Chains of epicenters as an indicator of the increasing correlation radius of seismicity before strong earthquakes. Vulkanologiya i Seismologiya Uournal of Volcanology and Seismology) (1), 3-15 (in Russian) [Шебалин П.Н. Цепочки эпицентров как индикатор возрастания радиуса корреляции сейсмичности перед сильными землетрясениями // Вулканология и сейсмология. 2005. № 1. С. 3-15].

Vil'kovich E.V., Shnirman M.G., 1980. On earthquake foci migration along large faults and Benioff zones. In: V.I. KeilisBorok, A.L. Levshin (Eds.), Methods and algorithms of seismic data interpretation. Computational Seismology, vol. 13. Nauka, Moscow, p. 19-24 (in Russian) [Вилькович Е.В., Шнирман М.Г. О миграции очагов землетрясений вдоль крупных разломов и зон Беньофа // Методы и алгоритмы интерпретации сейсмологических данных / Ред. В.И. Кейлис-Борок, А.Л. Левшин. Вычислительная сейсмология. Вып. 13. М.: Наука, 1980. C. 19-24].

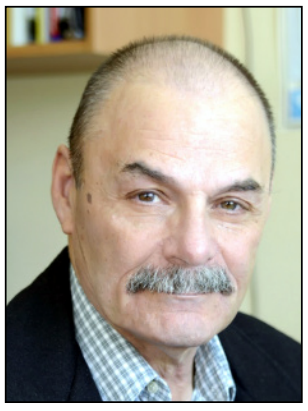

Гусев Александр Александрович, докт. физ.-мат. наук, заведующий лабораторией Институт вулканологии и сейсмологии ДВО РАН 683006, Петропавловск-Камчатский, бульвар Пийпа, 9, Россия

Камчатский филиал Геофизической службы РАН 683006, Петропавловск-Камчатский, бульвар Пийпа, 9, Россия 凶e-mail: gusev@emsd.ru

Gusev, Alexander A., Doctor of Physics and Mathematics, Head of Laboratory Institute of Volcanology and Seismology, Far East Branch of RAS

9 Piip Boulevard, Petropavlovsk-Kamchatsky 683006, Russia Kamchatka Division of Geophysical Survey of RAS

9 Piip Boulevard, Petropavlovsk-Kamchatsky 683006, Russia $\triangle$ e-mail: gusev@emsd.ru

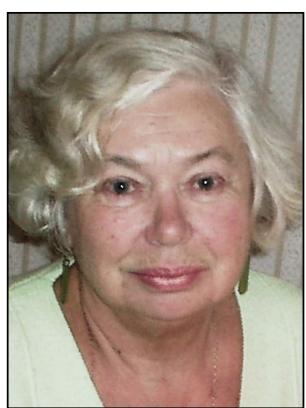

Палуева Аида Александровна, ведущий инженер

Институт вулканологии и сейсмологии ДВО РАН

683006, Петропавловск-Камчатский, бульвар Пийпа, 9, Россия

e-mail: palueva@kscnet.ru

Palueva, Aida A., Lead Engineer

Institute of Volcanology and Seismology, Far East Branch of RAS

9 Piip Boulevard, Petropavlovsk-Kamchatsky 683006, Russia

e-mail: palueva@kscnet.ru 